\title{
Hydrotalcite/unsaturated Carboxylic Acid Systems as Coagents in Ethylene-Propylene Copolymer Vulcanization
}

\author{
Magdalena Maciejewska*, Alicja Krzywania-Kaliszewska, Marian Zaborski \\ Technical University of Lodz, Institute of Polymer and Dye Technology, Lodz, 90-924, Poland
}

\begin{abstract}
The aim of this work was to study the activity of several hydrotalcite/unsaturated acid systems in the peroxide crosslinking of ethylene-propylene copolymer (EPM). Allylmalonic, citronellic, crotonic, itaconic, sorbic and undecylenic acids, as well as monoallyl maleate, were applied to ensure the activity of hydrotalcite in the peroxide vulcanization of EPM. In this article, we discuss the effect of the obtained coagents with respect to their particle size and tendency to agglomerate, as well as the effect of the applied type of unsaturated acid on the vulcanization kinetics of rubber compounds. The influence of hydrotalcite/unsaturated acid systems on the crosslink density, the mechanical properties of the vulcanizates and their stress relaxation tendency under external deformation were also studied. Hydrotalcite/unsaturated acid systems seem to be active as coagents in the crosslinking of EPM with peroxide. The type of unsaturated acid considerably influences the activity of hydrotalcite toward the ethylene-propylene copolymer. The application of such coagents increases the crosslink density of the vulcanizates and improves their mechanical properties.
\end{abstract}

Keywords Hydrotalcite, Coagent, Crosslinking, Ethylene-Propylene Copolymer, Vulcanization

\section{Introduction}

Peroxide vulcanization of polymers is a widely discussed process[1-5]. This process is usually used when good aging resistance, high processing temperature or good compression set at elevated temperature of rubber products is required[6]. However, there are some disadvantages of peroxide crosslinking compared to sulfur vulcanization. Usually, the tensile and tear strength of vulcanizates are reduced in comparison with those of conventionally sulfur-crosslinked samples[1,5]. To overcome this disadvantage and to extend the industrial application of peroxide-crosslinked elastomers, coagents are applied. According to Dluzneski, coagents are multifunctional vinyl monomers that are highly reactive toward the free radicals formed during peroxide vulcanization[2]. Coagents are able to undergo addition and polymerization reactions because their molecules contain double bonds. Because of the high reactivity of coagents toward peroxide radicals, the coagents can be easily grafted to elastomer chains, forming an interpenetrating crosslinked network. Moreover, functional groups of coagents are used to form ionic or complex crosslinks. In this way, coagents are incorporated into the polymer network[4,7]. Coagents can also suppress side reactions that occur during peroxide crosslinking (chain scission and

* Corresponding author:

magdalena.maciejewska@p.lodz.pl (Magdalena Maciejewska)

Published online at http://journal.sapub.org/materials

Copyright (C) 2011 Scientific \& Academic Publishing. All Rights Reserved disproportionation) and increase the crosslinking efficiency [7-9]. The most widely used coagents contain allylic, methacrylate, acrylate or maleimide groups[9]. Dikland et al. reported that the application of aliphatic bis (allyl) alkanediols and bis (allyl) poly (ethyleneglycol)s provided high crosslinking efficiencies in the peroxide crosslinking of EPM and reduced the vulcanization time of rubber compounds[4]. It was concluded that coagent bonds were formed as additional crosslinks because of graft polymerization of the allyl moieties of the coagent and covulcanization of coagent domains with the elastomer matrix. De Risi and Noordermeer applied methacrylate coagents to the peroxide curing of ethylene-propylene-diene elastomer and polypropylene blends[3]. The highest crosslinking activity occurred with trimethylol propane trimethacrylate, which also prevented the degradation of polypropylene through chain scission. In recent years, significant interest has been aroused by the application of zinc or magnesium salts of unsaturated carboxylic acids as coagents and fillers for elastomers[10-14]. These salts are formed in situ during the compounding and vulcanization of rubber mixes. Peng et al. reported that in situ prepared zinc dimethacrylate (ZDMA) improved the mechanical properties and crosslink density of ethylene-propylene-diene elastomer[10]. Peroxide initiated crosslinking of the polymer and polymerization of the ZDMA proceeded simultaneously during elastomer vulcanization. The vulcanizates contained both covalent and ionic crosslinks, which arose from the graft polymerization of ZDMA onto the EPDM chains. Similar results were obtained for acrylonitrile-butadiene rubber (NBR)[11], 
natural rubber[12], and other elastomers reinforced by in situ-formed zinc acrylate and methacrylate[13]. The reinforcement effect of in situ-prepared zinc stearate (ZDS) in NBR was also reported[14]. ZDS was formed by the reaction of zinc oxide with stearic acid during rubber compounding and vulcanization. The presence of ZDS increased the ionic crosslink content of the vulcanizates, their modulus tensile and tear strength.

In this work, we employed systems consisting of hydrotalcite and unsaturated carboxylic acids (HTA/UCA) as coagents for the crosslinking of ethylene-propylene copolymer with dicumyl peroxide. This method allowed hydrotalcite to act as the filler and coagent simultaneously. The unsaturated carboxylic acids contained easily- abstractable hydrogen atoms and readily-accessible double bonds that ensured their activity in the crosslinking process. Coagents were obtained during the modification process of hydrotalcite with allylmalonic, citronellic, crotonic, itaconic, sorbic and undecylenic acids, as well as monoallyl maleate. These coagents reacted with the elastomer chains to form covalent bonds. Additionally, ionic crosslinks were formed, thereby leading to an increase in the crosslink density of the vulcanizates and the improvement of their tensile strength. The influence of the HTA/UCA systems on the cure kinetics of rubber compounds and their crosslinking efficiency, vulcanizate crosslink density and tensile strength was discussed.

\section{Experimantal Section}

\subsection{Materials}

Ethylene-propylene copolymer EPM (Dutral CO 034) containing $28 \%$ of propylene was obtained from Polimeri Europa. Synthetic hydrotalcite (HTA, Aldrich) with the molecular formula $\mathrm{Mg}_{6} \mathrm{Al}_{2}\left(\mathrm{CO}_{3}\right)(\mathrm{OH})_{16} \cdot 4 \mathrm{H}_{2} \mathrm{O}$ was combined with unsaturated carboxylic acids. Nanosized silica (Aerosil 380, Degussa) was used as an active filler. The characteristics of the unsaturated carboxylic acids (UCA) are presented in Table 1.

Table 1. Characteristics of Unsaturated Carboxylic Acids

\begin{tabular}{|c|c|c|}
\hline Modifier & Linear Formula & Producer \\
\hline $\begin{array}{l}\text { Crotonic Acid } \\
\text { (CRA) }\end{array}$ & $\mathrm{CH}_{3} \mathrm{CH}=\mathrm{CHCOOH}$ & Aldrich \\
\hline $\begin{array}{l}\text { Sorbic Acid } \\
\text { (SA) }\end{array}$ & $\mathrm{CH}_{3} \mathrm{CH}=\mathrm{CHCH}=\mathrm{CHCOOH}$ & Aldrich \\
\hline $\begin{array}{c}\text { Itaconic Acid } \\
\text { (IA) }\end{array}$ & $\mathrm{HO}_{2} \mathrm{CCH}_{2} \mathrm{C}\left(=\mathrm{CH}_{2}\right) \mathrm{CO}_{2} \mathrm{H}$ & Fluka \\
\hline $\begin{array}{c}\text { Allylmalonic Acid } \\
\text { (ALA) }\end{array}$ & $\mathrm{CH}_{2}=\mathrm{CHCH}_{2} \mathrm{CH}(\mathrm{COOH})_{2}$ & Fluka \\
\hline $\begin{array}{l}\text { Citronellic Acid } \\
\text { (CIA) }\end{array}$ & $\left(\mathrm{CH}_{3}\right)_{2} \mathrm{C}=\mathrm{CHCH}_{2} \mathrm{CH}_{2} \mathrm{CH}\left(\mathrm{CH}_{3}\right) \mathrm{CH}_{2} \mathrm{CO}_{2} \mathrm{H}$ & Aldrich \\
\hline $\begin{array}{l}\text { Undecylenic Acid } \\
\text { (UA) }\end{array}$ & $\mathrm{CH}_{2}=\mathrm{CH}\left(\mathrm{CH}_{2}\right)_{8} \mathrm{COOH}$ & Aldrich \\
\hline $\begin{array}{l}\text { Monoallyl } \\
\text { Maleate } \\
\text { (MMA) }\end{array}$ & $\mathrm{HO}_{2} \mathrm{CCH}=\mathrm{CHCOOCH}_{2} \mathrm{CH}=\mathrm{CH}_{2}$ & $\begin{array}{c}\text { Technical } \\
\text { University } \\
\text { of Lodz }\end{array}$ \\
\hline
\end{tabular}

\subsection{Preparation of Coagents}

Hydrotalcite was mixed with solutions of the unsaturated acids in acetone for 30 minutes during ultrasonic treatment. The mixture was left for 24 hours. Next, the solvent (acetone) was evaporated using a vacuum evaporator at $50^{\circ} \mathrm{C}$. The modified hydrotalcites were dried in a vacuum drier at $60{ }^{\circ} \mathrm{C}$ for 96 hours. The quantity of unsaturated acid was $6 \mathrm{~g} / 100 \mathrm{~g}$ of hydrotalcite.

\subsection{Thermogravimetric Analysis of Coagents}

The coagents were thermally decomposed using a TGA/DSC1 (Mettler Toledo) analyzer. Samples were heated from $25^{\circ} \mathrm{C}$ to $800^{\circ} \mathrm{C}$ in an argon atmosphere at a heating rate of $10^{\circ} \mathrm{C} / \mathrm{min}$.

\subsection{Zeta Potential of Coagent Dispersions}

The surface properties of the hydrotalcite after treatment with the unsaturated acids were determined from zeta potential measurements made with a Zetasizer 2000 (Malvern Instruments) apparatus. The zeta potential of the coagent dispersions in water was measured as a function of $\mathrm{pH}$. The concentration of the dispersions was $0.1 \mathrm{~g} / \mathrm{L}$, and the $\mathrm{pH}$ was adjusted by the addition of an $\mathrm{HCl}$ or an $\mathrm{NaOH}$ solution.

\subsection{Hydrotalcite Aggregate Size}

The size of the hydrotalcite aggregates was determined using a Zetasizer Nano Series S90 (Malvern Instruments) apparatus. The size of the particles was measured by the DLS (Dynamic Light Scattering) method, as applied to suspensions of the particle in water. The concentration of the suspensions was $0.1 \mathrm{~g} / \mathrm{L}$.

Table 2. Composition of the EPM-Based Rubber Compounds (phr)

\begin{tabular}{|c|c|c|c|}
\hline EPM & 100 & 100 & 100 \\
\hline Dicumyl peroxide (DCP) & 3 & 3 & 3 \\
\hline Coagent (HTA/UCA) & - & 3 & 7 \\
\hline
\end{tabular}

\subsection{Preparation and Characterization of Rubber Compounds}

Rubber compounds with the formulations given in Table 2 were prepared using a laboratory two-roll mill. The samples were cured at $160^{\circ} \mathrm{C}$ until they developed a $90 \%$ increase in torque, which was measured by an oscillating disc rheometer. The crosslink density $\left(v_{T}\right)$ of the vulcanizates was determined by their equilibrium swelling in toluene based on the Flory-Rehner equation[15]. The Huggins parameter of the elastomer-solvent interaction $(\chi)$ was calculated from the equation $\chi=0.487+0.228 V_{r}$ (Equation (1))[16], where $V_{r}$ is the volume fraction of the elastomer in the swollen gel. In order to determine the content of ionic crosslinks in the elastomer network, samples were swollen in toluene in a desiccator with saturated ammonia vapor $(25 \%$ aqueous solution). The content of ionic crosslinks $(\Delta v)$ was calculated from Equation (2), where $v_{A}$ is the crosslink density determined for samples treated with ammonia vapor. 


$$
\Delta v=\frac{v_{T}-v_{A}}{v_{T}} \bullet 100 \%
$$

The tensile properties and stress relaxation (creep tests) of the vulcanizates were measured according to ISO-37 using a ZWICK 1435 universal machine. To determine the stress relaxation (creep) properties, a sample was subjected to prolonged constant tension at constant temperature. Deformation was recorded at specified time intervals $(0-10 \mathrm{~s}$, 10-100 s, 100-1000 s), and a stress relaxation (creep) versus time diagram was plotted. The slope of the curve at any point was a stress relaxation (creep) rate.

The dispersion of the coagent in the elastomer matrix was estimated using Scanning Electron Microscopy with a ZEISS SEM. The vulcanizates were broken down in liquid nitrogen, and the surfaces of their fractures were examined. Prior to measuring, the samples were coated with carbon.

The aging of vulcanizates under weather conditions was carried out for 100 hours with an Atlas CI 4000 "Xenon Arc Weather-Ometer" instrument. The aging process followed a simulated day-night cycle with the following parameters: day (102 minutes, irradiation of $60 \mathrm{~W} / \mathrm{m}^{2}, 367 \mathrm{~kJ}$, humidity $50 \%$, spray, temperature: black panel $80^{\circ} \mathrm{C}$, panel chamber $38^{\circ} \mathrm{C}$ ); night $\left(18\right.$ minutes, irradiation $60 \mathrm{~W} / \mathrm{m}^{2}, 64 \mathrm{~kJ}$, humidity $5 \%$, no spray, temperature: black panel $80^{\circ} \mathrm{C}$, panel chamber $38^{\circ} \mathrm{C}$ ). In order to estimate the resistance of the samples to weather aging, their mechanical properties and crosslink density after aging were determined and compared with the values obtained for the composites before aging. An aging factor $(\mathrm{K})$ was calculated as the numerical change in the mechanical properties of the samples upon aging (Equation 3):

$$
K=(T S \cdot E B)_{\text {after aging }} /(T S \cdot E B)_{\text {before aging }}
$$

\section{Results and Discussion}

\subsection{Efficiency of Coagent Preparation}

The presence of unsaturated organic acid in the coagents is crucial to ensure their activity in the crosslinking of the ethylene-propylene copolymer with dicumyl peroxide. Therefore, to confirm the presence of organic acids in coagents, thermogravimetric analysis of the modified hydrotalcites was performed. The weight loss of pure hydrotalcite during thermal decomposition and its weight loss after modification with unsaturated acids were compared to determine the presence of unsaturated acid in the HTA/UCA system, and the efficiency of the coagent preparation was calculated. These results are presented in Table 3 and Figure. 1.

The various unsaturated carboxylic acids (UCA) exhibited different reactivities toward hydrotalcite. Therefore, the efficiency of the modification of the hydrotalcite surface with UCA differed significantly and was in the range of 30.7 $-59.7 \%$. The highest contents of UCA in $100 \mathrm{~g}$ of coagent were achieved for undecylenic and allylmalonic acid, whereas the lowest values were achieved for crotonic and itaconic acid. The UCA content can be expected to affect the activity of the coagent considerably during elastomer crosslinking.

Table 3. Thermogravimetric Analysis of Coagents

\begin{tabular}{|c|c|c|}
\hline Coagent & $\begin{array}{c}\text { Total Weight Loss During } \\
\text { Decomposition (\%) }\end{array}$ & $\begin{array}{c}\text { Efficiency of Coagent } \\
\text { Preparation (\%) }\end{array}$ \\
\hline HTA & 42.8 & - \\
\hline HTA/CRA & 44.6 & 30.7 \\
\hline HTA/SA & 44.9 & 42.8 \\
\hline HTA/IA & 44.7 & 31.7 \\
\hline HTA/ALA & 45.8 & 50.0 \\
\hline HTA/CIA & 45.0 & 37.5 \\
\hline HTA/UA & 46.9 & 59.7 \\
\hline HTA/MMA & 44.9 & 36.3 \\
\hline
\end{tabular}

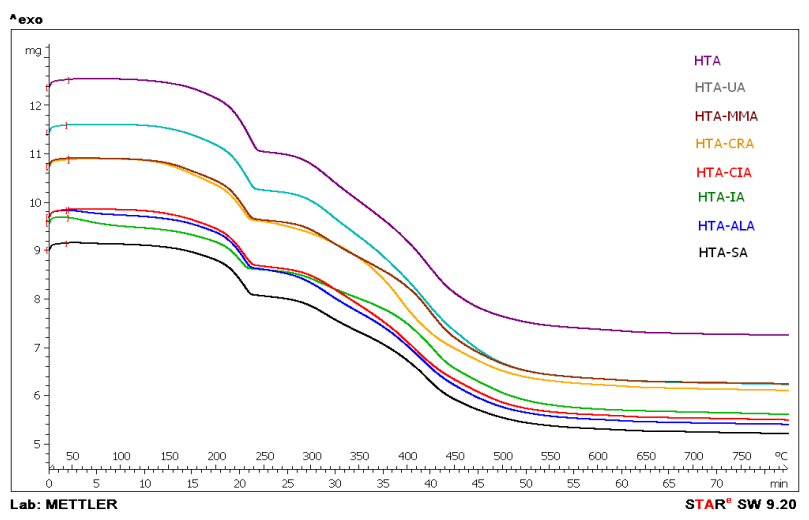

Figure 1. TGA thermograms of coagents

The presence of UCA in the coagents was also confirmed by the results of the zeta potential measurements of the water dispersion of the coagents. The zeta potential is an electrokinetic potential measured on the surface of a solid particle in solution. A charged surface results in the formation of an electric double layer. The zeta potential is the potential between the surface of the charged particle and the electrolyte solution[17]. The zeta potential of the water-coagent dispersions was measured as a function of $\mathrm{pH}$ (Figure. 2).

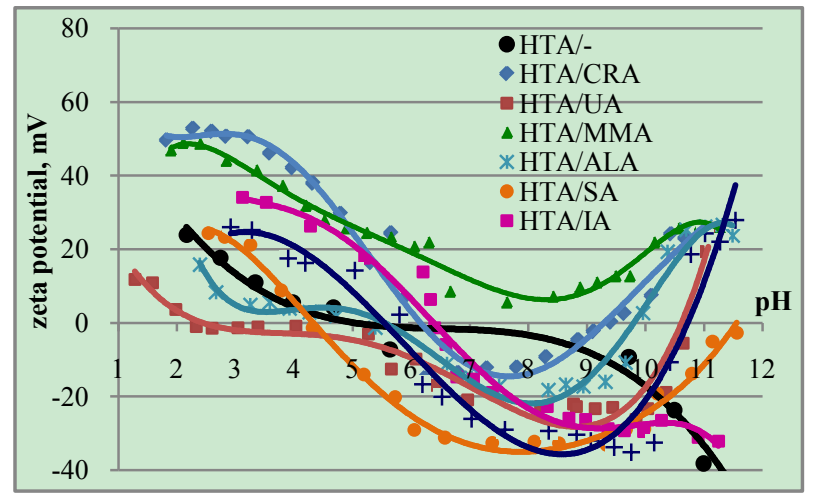

Figure 2. Zeta potential of coagent dispersions, as a function of $\mathrm{pH}$

From these measurements, the isoelectric points (IEP, the $\mathrm{pH}$ value at which the zeta potential is equal to zero) of the coagents were determined (Table 4). IEP is a description of the relative basicity or acidity of solid surface. A high IEP value indicates that the solid surface shows more basic functionality than acidic functionality. Therefore, the pres- 
ence of unsaturated carboxylic acids in the coagents should considerably influence their zeta potential. The isoelectric point (IEP) of pure HTA was determined to occur at pH 4.9. Above this $\mathrm{pH}$, the zeta potential was negative. The progress of the zeta potential curve showed the relatively acidic character of the pure HTA surface. For most coagents, two IEPs were observed; the first was found in an acidic medium and the other in an alkaline medium. Based on these results, it could be concluded that the presence of UCA resulted in an amphoteric surface character of the hydrotalcite. HTA/MMA was found to be an exception, showing basic properties. The zeta potential values were positive over the entire investigated range of $\mathrm{pH}$, and an isoelectric point was not observed for this coagent.

The results of the zeta potential measurements proved that UCA was present in the coagents. This result is important because the unsaturated chains of UCA play a crucial role in the crosslinking of the elastomer and are responsible for coagent reactivity.

Table 4. IEP Values of Coagent Dispersions

\begin{tabular}{|c|c|c|}
\hline Coagent & IEP $1(\mathrm{pH})$ & IEP $2(\mathrm{pH})$ \\
\hline HTA & 4.9 & - \\
\hline HTA/CRA & 6.2 & 9.4 \\
\hline HTA/SA & 4.3 & 11.5 \\
\hline HTA/IA & 6.4 & - \\
\hline HTA/ALA & 4.8 & 9.8 \\
\hline HTA/CIA & 4.8 & 10.7 \\
\hline HTA/UA & 2.4 & 10.6 \\
\hline HTA/MMA & - & - \\
\hline
\end{tabular}

\subsection{Coagents Particles Size}

The particle size of the coagent is a parameter with a great influence on coagent activity. A reduction of the particle size results in an increase in the coagent specific surface area, thereby providing better contact between its particles and the elastomer chains. The sizes of the coagent particles measured in water dispersion are presented in Table 5.

Table 5. Coagent Agglomerate Size Measured in Water

\begin{tabular}{|c|c|c|c|}
\hline Coagent & $\begin{array}{c}\text { Particle } \\
\text { Size }(\mathrm{nm})\end{array}$ & $\begin{array}{c}\text { Size of the Particle } \\
\text { Main Fraction }(\mathrm{nm})\end{array}$ & Number \% \\
\hline HTA & $234-331$ & 262 & 38 \\
\hline HTA/CRA & $262-331$ & 295 & 42 \\
\hline HTA/SA & $262-417$ & 330 & 37 \\
\hline HTA/IA & $208-295$ & 234 & 43 \\
\hline HTA/ALA & $330-468$ & 417 & 43 \\
\hline HTA/CIA & $294-469$ & 372 & 38 \\
\hline HTA/UA & $185-262$ & 234 & 38 \\
\hline HTA/MMA & $208-295$ & 234 & 38 \\
\hline
\end{tabular}

The size of the pure HTA particles was in the range of $234-331 \mathrm{~nm}$, with the main fraction having a size of $262 \mathrm{~nm}$. Only itaconic acid, undecylenic acid and monoallyl maleate caused a decrease in the average particle size of HTA to 234 $\mathrm{nm}$. Other unsaturated carboxylic acids increased the size of the HTA particles to $295 \mathrm{~nm}$ (HTA/CRA), $330 \mathrm{~nm}$ (HTA/SA), $372 \mathrm{~nm}$ (HTA/CIA) and $417 \mathrm{~nm}$ (HTA/ALA).

The sizes of the coagent particles were also measured in a liquid hydrophobic medium, paraffin oil, which was chosen as the model for an elastomer matrix (Table 6). The aim of this study was to estimate the tendency of coagent particles to agglomerate in elastomer.

Particles of pure HTA revealed a tendency to agglomerate in paraffin oil, thereby creating agglomerates of approximately $10 \mu \mathrm{m}$ in size. Therefore, the particles can also be expected to agglomerate in the elastomer. The application of monoallyl maleate, undecylenic and itaconic acid considerably reduced the ability of HTA particles to agglomerate. The agglomerates produced in paraffin oil were approximately $3 \mu \mathrm{m}$ smaller than the pure HTA agglomerates. The largest agglomerates in paraffin oil were formed by the particles of HTA/SA and HTA/ALA, indicating that it will be difficult to obtain a homogeneous dispersion of those particles in the elastomer matrix.

Table 6. Coagent Agglomerate Size Measured in Paraffin Oil

\begin{tabular}{|c|c|}
\hline Coagent & Agglomerate Size $(\mu \mathrm{m})$ \\
\hline HTA & 10.0 \\
\hline HTA/CRA & 8.9 \\
\hline HTA/SA & 11.6 \\
\hline HTA/IA & 7.5 \\
\hline HTA/ALA & 12.9 \\
\hline HTA/CIA & 10.5 \\
\hline HTA/UA & 7.1 \\
\hline HTA/MMA & 6.5 \\
\hline
\end{tabular}

\subsection{Coagent Dispersion in Elastomer}

SEM images of the vulcanizate surfaces were taken to examine directly the dispersion of coagent particles in the elastomer. These results are presented in Figure. 3 (a-d).

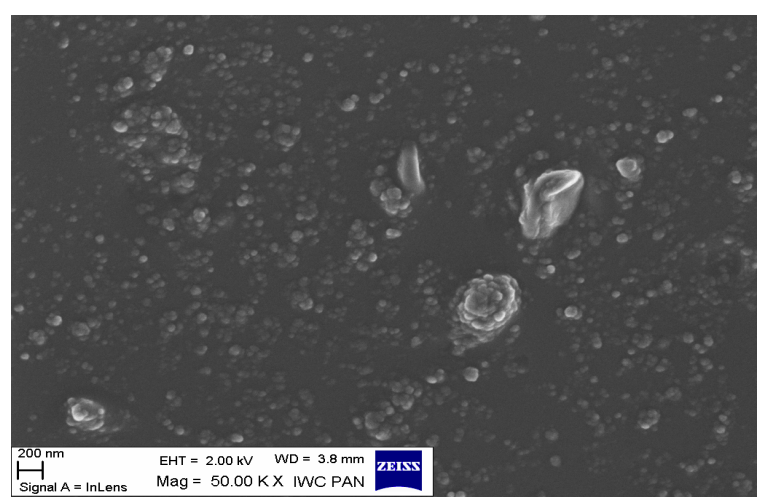

a)

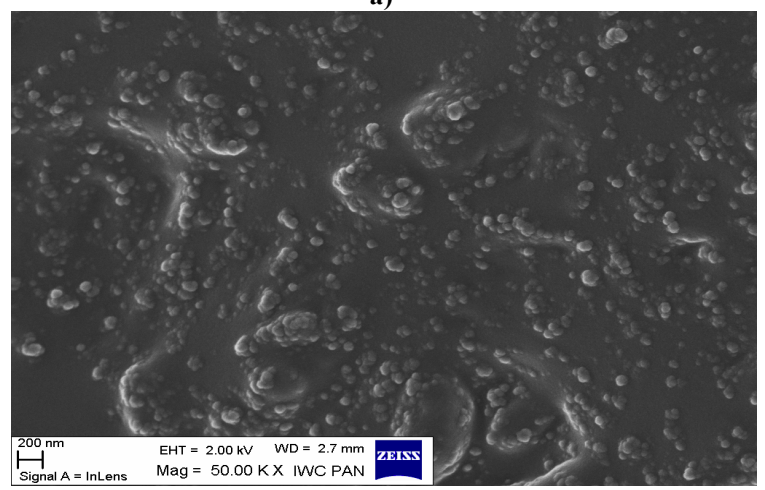

b) 


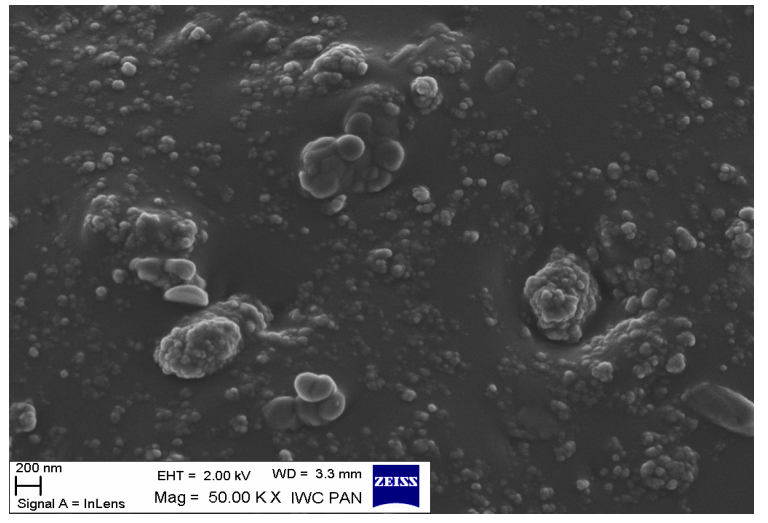

c)

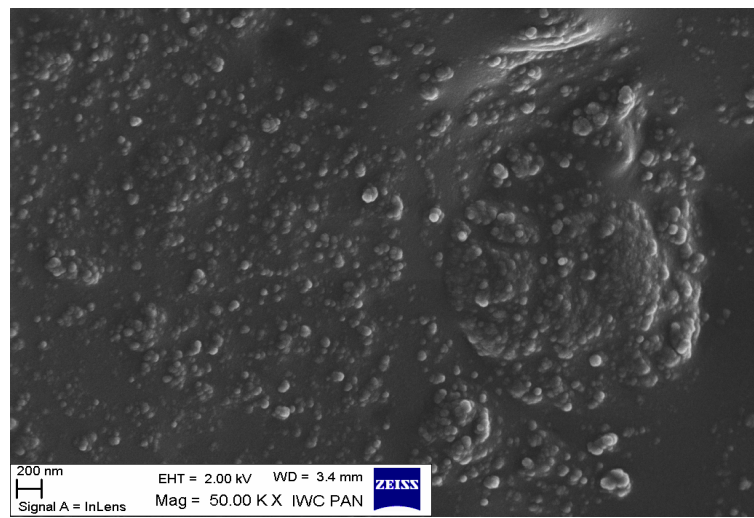

d)

Figure 3. SEM images of vulcanizates containing: a) HTA/IA, b) HTA/ UA, c) HTA/SA, d) HTA/ALA

The vulcanizates were filled with silica, and those particles were homogeneously distributed in the elastomer. Unfortunately, the SEM images confirm our conclusion from the particle-size measurements in paraffin oil: the coagent particles did agglomerate in the elastomer.

Particles of HTA/IA and HTA/UA (Figure. 3a and $3 b$ ) were homogeneously dispersed in the elastomer. The particles created agglomerates less than $1 \mu \mathrm{m}$ in size, which were surrounded by an elastomer film and tightly bound to the elastomer matrix. The wetting of coagent clusters with elastomer should result in good mechanical properties of the vulcanizates, despite the particle agglomeration. The HTA/SA and HTA/UA particles exhibited the strongest tendency to agglomerate. These particles created clusters that were several $\mu \mathrm{m}$ in size (Figure. $3 \mathrm{c}$ and $3 \mathrm{~d}$ ), which were heterogeneously distributed in the elastomer, especially in the case of HTA/SA.

Assuming that the coagent particles diffuse through the elastomer matrix and react with elastomer chains, forming ionic crosslinks, their dispersion in the elastomer should have a significant impact on the activity of the coagents and their influence on the vulcanizate properties. These influences will be discussed in the following sections.

\subsection{Cure Characteristics and Crosslink Density of Vulcanizates}

The main goal of coagent application is the improvement of the crosslinking efficiency and increased crosslink density of the vulcanizates. We believed that the application of coagents based on hydrotalcite in combination with unsaturated carboxylic acid would result in the formation of additional ionic crosslinks, which should improve the crosslink density of the vulcanizates.

To examine the activity of the coagents in crosslinking process, the cure characteristics of the rubber compounds were determined. These results are presented in Table 7.

Table 7. Cure Characteristics and Crosslink Density of EPM Composites Containing Coagents $(\Delta \mathrm{G}$ - Increment of Torque in the Rubber Compound During Vulcanization; $t_{90}$ - Optimal Vulcanization Time; $t_{\mathrm{p}}$ - Scorch Time)

\begin{tabular}{|c|c|c|c|c|c|c|}
\hline Coagent & $\begin{array}{c}\text { Coagent } \\
\text { Content } \\
(\mathrm{phr})\end{array}$ & $\begin{array}{c}\Delta \mathrm{G} \\
(\mathrm{dNm})\end{array}$ & $\begin{array}{c}\mathrm{t}_{90} \\
(\mathrm{~min})\end{array}$ & $\begin{array}{c}\mathrm{t}_{\mathrm{p}} \\
(\mathrm{s})\end{array}$ & $\begin{array}{c}v_{\mathrm{t}} * 10^{-5} \\
\left(\mathrm{~mol} / \mathrm{cm}^{3}\right)\end{array}$ & $\begin{array}{c}\Delta v \\
(\%)\end{array}$ \\
\hline- & - & 36.4 & 12 & 131 & 1.04 & 11.6 \\
\hline HTA/CRA & 3 & 73.2 & 12 & 107 & 4.34 & 37.6 \\
\hline HTA/CRA & 7 & 80.1 & 12 & 97 & 4.95 & 31.5 \\
\hline HTA/SA & 3 & 91.6 & 12 & 100 & 4.23 & 31.0 \\
\hline HTA/SA & 7 & 95.6 & 12 & 92 & 4.57 & 24.9 \\
\hline HTA/IA & 3 & 84.9 & 15 & 128 & 4.03 & 34.2 \\
\hline HTA/IA & 7 & 90.8 & 16 & 100 & 4.97 & 19.9 \\
\hline HTA/ALA & 3 & 91.1 & 16 & 116 & 4.03 & 30.8 \\
\hline HTA/ALA & 7 & 87.6 & 15 & 124 & 3.90 & 22.6 \\
\hline HTA/CIA & 3 & 93.3 & 15 & 114 & 4.30 & 33.0 \\
\hline HTA/CIA & 7 & 96.4 & 16 & 106 & 4.39 & 22.8 \\
\hline HTA/UA & 3 & 81.1 & 17 & 122 & 4.99 & 34.0 \\
\hline HTA/UA & 7 & 83.8 & 13 & 99 & 5.79 & 32.5 \\
\hline HTA/MMA & 3 & 79.0 & 22 & 138 & 4.93 & 34.5 \\
\hline HTA/MMA & 7 & 85.4 & 23 & 119 & 5.69 & 27.8 \\
\hline
\end{tabular}

The rubber compound crosslinked only with dicumyl peroxide and without the addition of coagent was characterized by an increase of torque during vulcanization by approximately $36 \mathrm{dNm}$. The application of coagents caused a nearly fourfold increase in the torque increment compared to the conventional rubber compound. The torque increment during vulcanization is an indirect measurement of the degree of elastomer crosslinking. Therefore, it can be concluded that the coagents are actively involved in the crosslinking process. The highest values of the torque increase were achieved for rubber compounds containing HTA modified with sorbic, itaconic, allylmalonic and citronellic acids. The coagent content of the elastomer did not considerably affect the torque increase during vulcanization.

The active participation of coagents in EPM crosslinking was confirmed by the values of the vulcanizate crosslink density determined from their equilibrium swelling in toluene. Vulcanizates containing coagents exhibited crosslink densities four times higher than the pure peroxide-crosslinked vulcanizate. The crosslink density of EPM vulcanizates was probably improved by the formation of additional ionic crosslinks in the presence of HTA/UCA coagents (Table 7). The vulcanizates without coagents exhibited a non-covalent link content of approximately $11.6 \%$. These bonds probably occurred at the rubber-silica interface. The coagents had no influence on the amount of silica-elastomer bonds. Therefore, the difference between the number of non-covalent links determined for the vulcani- 
zates containing coagents and the number of the links at the silica-elastomer interface corresponds to the content of non-covalent crosslinks in the elastomer network resulting from coagent action. These crosslinks are probably labile ionic crosslinks. The highest content of ionic crosslinks in the elastomer network was achieved for vulcanizates crosslinked with HTA/CRA and HTA/UA (more than 20\%). The content of ionic crosslinks decreased as the coagent content in the elastomer increased. This trend could be attributed to the agglomeration of coagent particles in the elastomer or the poor solubility of the coagent in the elastomer matrix.

The effect of coagents on the vulcanization and scorch time of rubber compounds was also examined. HTA in combination with CRA or SA did not affect the vulcanization time. However, HTA led to the shortening of scorch time by approximately 30 seconds from the time observed for the peroxide-crosslinked composite. Other coagents increased the vulcanization time by intervals in the range of 15-23 minutes. A slight decrease in the scorch time was also observed for these rubber compounds. The coagent content had no significant effect on the vulcanization time.

\subsection{Mechanical Properties of Vulcanizates}

The influence of coagents on the crosslinking activity of the ethylene-propylene copolymer was estimated from the tensile properties of the vulcanizates. The presence of labile ionic crosslinks in the elastomer network should improve the tensile strength and stress relaxation ability of the vulcanizates. These results are given in Table 8 .

The results summarized in Table 8 clearly show a high activity of hydrotalcite based coagents in the crosslinking process and a corresponding positive impact on the properties of the vulcanizates.

Table 8. Mechanical Properties of EPM Vulcanizates Containing Coagents $\left(\mathrm{SE}_{300}\right.$ - Modulus at $300 \%$ Vulcanizate Relative Elongation; EB Elongation at Break)

\begin{tabular}{|c|c|c|c|c|}
\hline Coagent & $\begin{array}{c}\text { Coagent } \\
\text { Content }(\mathrm{phr})\end{array}$ & $\begin{array}{c}\mathrm{SE}_{300} \\
(\mathrm{MPa})\end{array}$ & $\mathrm{TS}(\mathrm{MPa})$ & EB (\%) \\
\hline- & - & 2.71 & 8.8 & 1009 \\
\hline HTA/CRA & 3 & 3.48 & 20.2 & 716 \\
\hline HTA/CRA & 7 & 3.85 & 17.9 & 680 \\
\hline HTA/SA & 3 & 3.12 & 21.5 & 650 \\
\hline HTA/SA & 7 & 3.09 & 17.4 & 649 \\
\hline HTA/IA & 3 & 3.21 & 24.1 & 714 \\
\hline HTA/IA & 7 & 3.63 & 22.5 & 663 \\
\hline HTA/ALA & 3 & 3.00 & 23.4 & 717 \\
\hline HTA/ALA & 7 & 3.10 & 23.3 & 759 \\
\hline HTA/CIA & 3 & 2.98 & 20.9 & 682 \\
\hline HTA/CIA & 7 & 2.79 & 15.8 & 624 \\
\hline HTA/UA & 3 & 3.47 & 20.8 & 686 \\
\hline HTA/UA & 7 & 3.81 & 19.0 & 651 \\
\hline HTA/MMA & 3 & 3.76 & 23.6 & 677 \\
\hline HTA/MMA & 7 & 4.24 & 20.9 & 694 \\
\hline
\end{tabular}

At $300 \%$ elongation, the peroxide-crosslinked EPM vulcanizate containing $3 \mathrm{phr}$ of dicumyl peroxide exhibited a modulus equal to $2.71 \mathrm{MPa}$, a tensile strength of approximately $9 \mathrm{MPa}$ (despite the active filler application) and an elongation at break of over $1000 \%$. Such a large elongation at break shows that this vulcanizate was not optimally crosslinked. The application of coagents caused an increase of the vulcanizate crosslink density, as mentioned earlier. This increase was indicated by an increase in the value of $\mathrm{SE}_{300}$ to a value above $3 \mathrm{MPa}$ and a reduction of the elongation at break to the optimal range of $614-750 \%$. These results confirm that the applied coagents participated in the formation of ionic crosslinks in the elastomer network, and the presence of these labile crosslinks improved the mechanical properties of the vulcanizates.

One of the most important parameters determining the potential application of elastomeric materials is their tensile strength. HTA/UCA coagents significantly improved the tensile strength of the EPM vulcanizates. The use of coagents increased the tensile strength by two or even three times beyond the tensile strength of the peroxide-crosslinked vulcanizate. The highest tensile strength was exhibited by vulcanizates containing HTA/IA (approximately $24 \mathrm{MPa}$ ) or HTA/ALA (23 MPa). The tensile strength of the vulcanizates decreased as the coagent content increased, probably because of the agglomeration of coagent particles in the elastomer (as confirmed by the SEM images). The agglomerates acted as stress concentrating centers in the sample when it was subjected to external deformations, causing the sample to fail more quickly. It is possible that the improvement of the tensile strength of the vulcanizates was partially a result of the reinforcing effect of the HTA in the EPM. Moreover, agglomeration decreased the activity of the coagent in the crosslinking process and, consequently, the content of ionic crosslinks (see Table 7), which are primarily responsible for the increase of tensile strength.

The presence of strong and multifunctional labile ionic clusters, which are able to move on the surface of the solid HTA particles, should result in improved stress-relaxation ability of the vulcanizates. To confirm this assumption, stress relaxation measurements (creep tests) were performed on the coagents containing vulcanizates. The results for several sample vulcanizates are given in Table 9.

Table 9. Stress Relaxation Rates (Creep Rates) of EPM Vulcanizates Containing 3 phr of Coagents $\left(\mathrm{n}_{1}, \mathrm{n}_{2}, \mathrm{n}_{3}\right.$ - Rates of Stress Relaxation for the Time Intervals 0-10 s, 10-100 s, 100-1000 s, Respectively)

\begin{tabular}{|c|c|c|c|}
\hline Coagent & $\begin{array}{c}\mathrm{n}_{1} * 10^{-3} \\
\left(\mathrm{~s}^{-1}\right)\end{array}$ & $\begin{array}{c}\mathrm{n}_{2} * 10^{-3} \\
\left(\mathrm{~s}^{-1}\right)\end{array}$ & $\begin{array}{c}\mathrm{n}_{3} * 10^{-3} \\
\left(\mathrm{~s}^{-1}\right)\end{array}$ \\
\hline- & 240.9 & 84.7 & 80.8 \\
\hline HTA/IA & 271.1 & 88.6 & 100.0 \\
\hline HTA/ALA & 263.9 & 100.8 & 184.4 \\
\hline HTA/MMA & 273.6 & 131.7 & 151.1 \\
\hline
\end{tabular}

The application of coagents increased the stress relaxation rates of the vulcanizates at all stages of the stress relaxation process. The first stage of stress relaxation was characterized by a rapid rate $\left(\mathrm{n}_{1}\right)$, which slowed with time. The second stage had a relatively uniform rate $\left(\mathrm{n}_{2}\right)$. In the third stage of the stress relaxation process, the rate $\left(n_{3}\right)$ increased again, reaching a value above the rate of the second stage.

These results confirm that the tensile strength improvement of the vulcanizates is also partially caused by the in- 
crease of the vulcanizates stress relaxation ability. The considerable chain slippage and reformation of ionic bonds in the elastomer network under external stress contribute to the increase in the vulcanizate tensile strength.

\subsection{Resistance of Vulcanizates to Weather Aging}

One of the most important properties of saturated elastomers crosslinked with peroxides is their strong aging resistance. Therefore, the effect of coagents on vulcanizate resistance to weather aging was examined through the change in their mechanical properties and crosslink density. We expected that the presence of coagents based on minerals with a layered structure would protect the polymer against the aging process.

In Figure. 4, the change in elongation at break upon weather aging is given for vulcanizates containing $7 \mathrm{phr}$ of coagent.

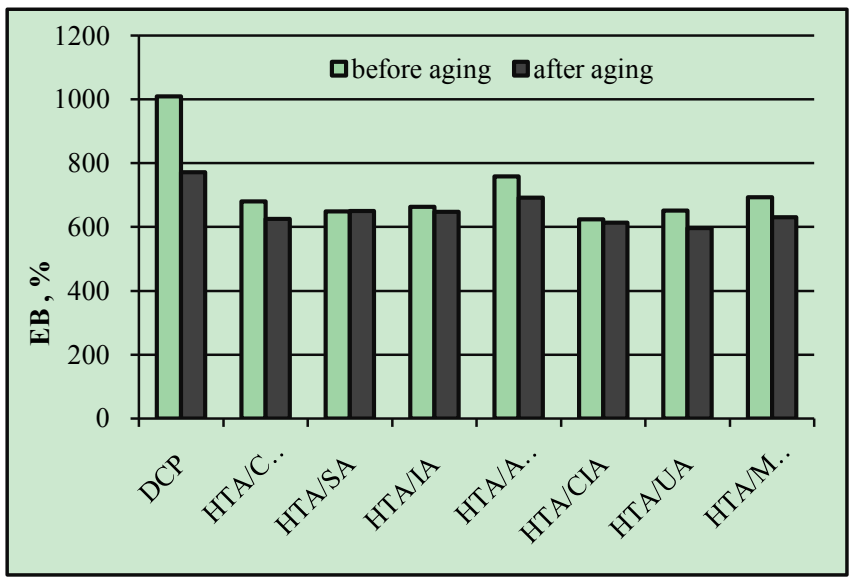

Figure 4. Vulcanizate elongation at break after weather aging

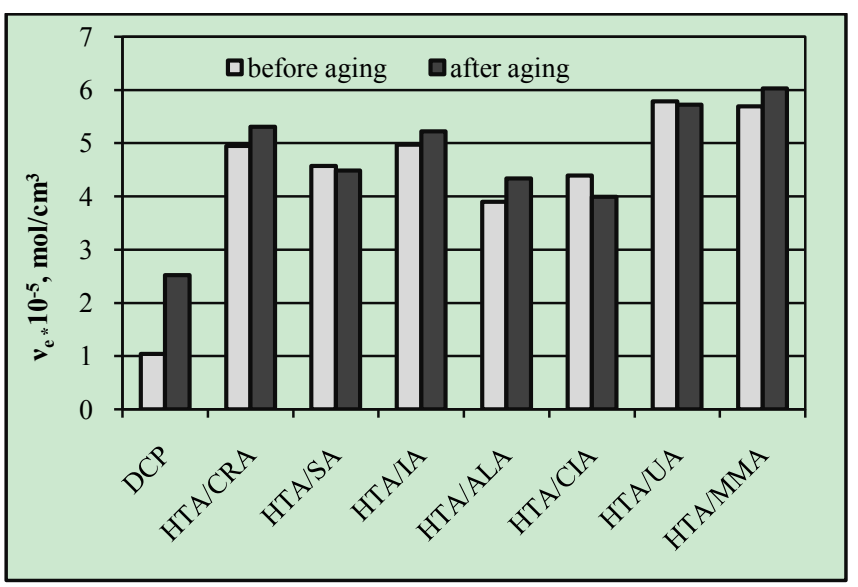

Figure 5. Vulcanizate crosslink density after weather aging

Weather aging had a considerable impact on the elongation at break of the peroxide crosslinked vulcanizate, causing it to decrease by approximately $300 \%$ (Figure. 4). This change reflects the large increase in the crosslink density of the vulcanizate. Under the influence of aging factors, such as UV radiation and elevated temperature, further crosslinking of the elastomer took place. In the case of vulcanizates containing coagents, weather aging had no significant effect on the elongation at break, meaning that the extent of further crosslinking of the elastomer was greatly reduced. This conclusion was confirmed by the results of the crosslink density measurements that are presented in Figure. 5. Weather aging caused a twofold increase in the crosslink density of the pure peroxide vulcanizate. In the case of the vulcanizates containing coagents, aging was observed to have only a small effect on the crosslink density.

Despite small changes in the elongation at break and crosslink density of vulcanizates with coagents, weather aging deteriorated their tensile strength, as it did to the pure peroxide vulcanizate. The least change in tensile strength was achieved for the vulcanizate containing HTA/SA (Figure. 6).

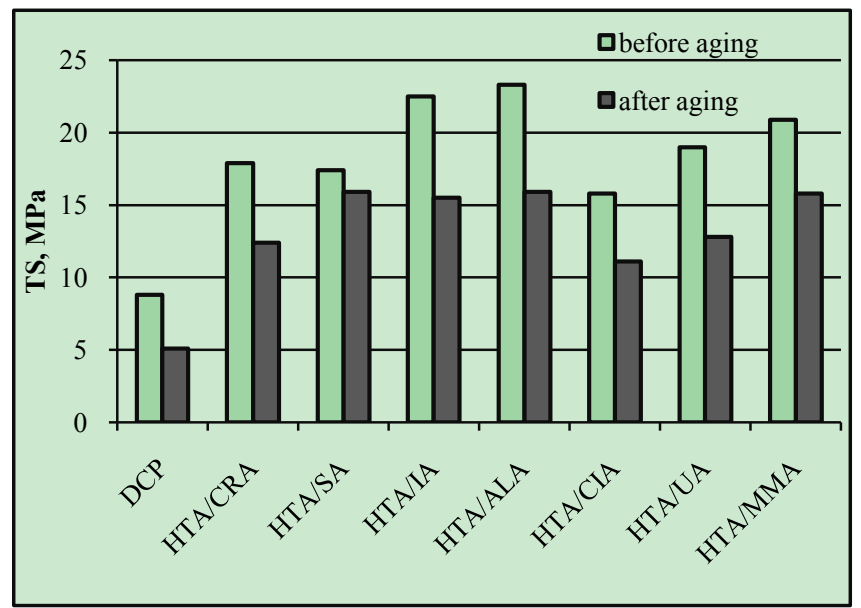

Figure 6. Vulcanizate tensile strength after weather aging

To quantitatively estimate the change in the mechanical properties of vulcanizates because of weather aging, the aging factor $\mathrm{K}$ was calculated (Table 10). This factor is a measurement of changes in the sample deformation energy caused by the aging process. Values of the K-factor that are closer to 1 indicate smaller changes in the mechanical properties of the vulcanizates from the aging process.

Table 10. Weather Aging Factor (K) of EPM Vulcanizates Containing $7 \mathrm{phr}$ of Coagents

\begin{tabular}{|c|c|}
\hline Coagent & $\mathrm{K}(-)$ \\
\hline- & 0.44 \\
\hline HTA/CRA & 0.64 \\
\hline HTA/SA & 0.92 \\
\hline HTA/IA & 0.67 \\
\hline HTA/ALA & 0.56 \\
\hline HTA/CIA & 0.69 \\
\hline HTA/UA & 0.62 \\
\hline HTA/MMA & 0.67 \\
\hline
\end{tabular}

The aging factor $(\mathrm{K})$ for pure peroxide vulcanizate is 0.44 . The application of coagents increased the values of $\mathrm{K}$ considerably. This difference is the result of small changes in the elongation at break of the vulcanizates. The highest value of $\mathrm{K}$ was observed for the vulcanizate containing the HTA/SA coagent and was close to 1 . This coagent provided the best protection for the EPM copolymer against weather aging. 


\section{Conclusions}

Hydrotalcite, in combination with unsaturated carboxylic acids, was used as coagent for peroxide-crosslinking of an ethylene-propylene copolymer. The presence of UCA in the coagents was confirmed by the results of zeta potential measurements and thermogravimetric analysis.

We conclude that the application of coagents allowed for the realization of vulcanizates with considerably improved mechanical properties and higher crosslink density compared to vulcanizates crosslinked only with peroxide. The crosslink density of EPM vulcanizates was probably improved by the formation of additional ionic crosslinks in the presence of the coagents. The highest ionic crosslink content in the elastomer network was achieved for vulcanizates crosslinked with HTA/CRA and HTA/UA. The ionic crosslink content decreased with the increasing amount of coagent in the elastomer, probably because of the agglomeration of coagent particles in the elastomer, which was confirmed by SEM images. Coagents increased the tensile strength to two or even three times that of the peroxide-crosslinked vulcanizate. The improvement of the tensile strength of the vulcanizates was partially caused by the increase of their stress relaxation ability, as a result of the ionic crosslinks present in the elastomer network.

Coagents increased the resistance of vulcanizates to weather aging. Further crosslinking of the elastomers containing coagents during the aging process was greatly reduced in comparison with the purely peroxide-crosslinked vulcanizate. Only a small effect of aging on the crosslink density was observed for vulcanizates with coagents.

\section{ACKNOWLEDGEMENTS}

The authors wish to acknowledge the Polish Ministry of Science and Higher Education and the National Center for Research and Development for supporting this research.

\section{REFERENCES}

[1] Henning, S. K., Costin, R., 2006, Fundamentals of curing elastomers with peroxides and coagents, Rubber World, 233, 28-35

[2] Dluzneski, P. R., 2001, Peroxide vulcanization of elastomers, Rubber Chemistry and Technology, 74, 451-492

[3] De Risi, F. R., Noordermeer, J. W. M., 2007, Effect of methacrylate co-agents on peroxide cured PP/EPDM thermop- lastic vulcanizates, Rubber Chemistry and Technology, 80, 83-99

[4] Dikland, H. G., Ruardy, T., van der Does, L., Bantjes, A., 1993, New coagents in peroxide vulcanization of EPM, Rubber Chemistry and Technology, 66, 693-711

[5] Alvarez-Grima, M. M., Talma, A. G., Datta, R. N., Noordermeer, J. W. M., 2006, New concept of co-agents for scorch delay and property improvement in peroxide vulcanization, Rubber Chemistry and Technology, 79, 694-711

[6] Class, J., 1999, A review of the fundamentals of crosslinking with peroxides, Rubber World, 220, 35-39

[7] Garcia - Quesada, J. C., Gilbert, M., 2000, Peroxide crosslinking of unplasticized poly(vinyl chloride), Journal of Applied Polymer Science, 77, 2657-2666

[8] Bucsi, A., Szocs, F., 2000, Kinetics of radical generation in PVC with dibenzoyl peroxide utilizing high-pressure technique, Macromolecular Chemistry and Physics, 201, 435-438

[9] Dikland, H. G., Hulskotte, R. J. M., 1993, The mechanism of EPDM peroxide vulcanizations in the presence of triallylcyanurate as coagent, Kautschuk und Gummi Kunststoffe, 46, 608-613

[10] Peng, Z., Liang, X., Zhang, Y., Zhang, Y., 2002, Reinforcement of EPDM by in situ prepared zinc dimethacrylate, Journal of Applied Polymer Science, 84, 1339-1345

[11] Yuan, X., Peng, Z., Zhang, Y., Zhang, Y., 2000, In situ preparation of zinc salts of unsaturated carboxylic acids to reinforce NBR, Journal of Applied Polymer Science, 77, $2740-2748$

[12] Nie, Y., Huang, G., Qu, L., Zhang, P., Weng, G., Wu, J., 2010, Cure kinetics and morphology of natural rubber reinforced by the in situ polymerization of zinc dimethacrylate, Journal of Applied Polymer Science, 115, 99-106

[13] Lu, Y., Liu, L., Tian, M., Geng, H., Zhang, L., 2005, Study on mechanical properties of elastomers reinforced by zinc dimethacrylate, European Polymer Journal, 41, 589-598

[14] Guo, B. C., Chen, F., Chen, W. W., Lei, Y. D., Jia, D. M., 2010, Reinforcement of nitrile rubber by in situ formed zinc disorbate, eXRESS Polymer Letters, 4, 529-538

[15] Flory, P. J., Rehner, J., 1943, Statistical mechanics of cross-linked polymer networks. II. Swelling, Journal of Chemical Physics, 11, 521-526

[16] Maciejewska, M., Zaborski M., 2010, Coagents of peroxide crosslinking of elastomers, Przemysl Chemiczny, 89(4), 472-477

[17] Zecchina, A., Lamberti, C., Bordiga, S., 1998, Surface acidity and basicity: General concepts, Catalysis Today, 41, 169-177 